Quality : Jurnal Kesehatan

Volume 14, Nomor 2 Tahun 2020

pISSN : 1978-4325, eISSN : 2655-2434, DOI: 10.36082/qjk.v14i2.101

\title{
Efektifitas penggunaan sikat gigi double care dan konvensional terhadap Debris Index
}

\author{
Eka Anggreni ${ }^{1}$, Erwin ${ }^{2}$ \\ 1,2 Jurusan Keperawatan Gigi, Politeknik Kesehatan Kemenkes Jakarta I, Indonesia
}

\begin{abstract}
Info Artikel Abstrak
Genesis :

Submitted: 13-04-2020

Revised: 09-09-2020

Accepted: 1-12-2020

\section{Kata Kunci :}

Debris Indeks, Sikat

Gigi Double Care,

Sikat gigi

Konvensional, Murid

Timbulnya karies dan penyakit periodontal diawali dengan adanya akumulasi bakteri plak yang menumpuk pada permukaan gigi, usaha untuk membersihkannya dengan melakukan pembuangan plak antara lain menggunakan sikat gigi. Penggunaan sikat gigi dalam oral fisioterapi penting untuk diperhatikan, karena dipasaran ditemukan beberapa macam sikat gigi dengan berbagai jenis bulu sikat gigi. Penggunaan sikat gigi yang salah akan mengurangi keefektifan dalam membersihkan plak di permukaan gigi. Tujuan penelitian ini adalah menganalisis efektifitas penggunaan sikat gigi double care dan sikat gigi konvensional terhadap Debris Index pada siswa SDN 05 Cilandak Timur Tahun 2019. Jenis penelitian ini adalah quasi experiment, sampel dalam penelitian ini adalah murid SDN 05 Cilandak Timur berjumlah 32 orang yang diambil dengan teknik purposive sampling. Hasil penelitian menunjukkan nilai uji statistik Mann Whitney diperoleh nilai $\rho$-value : $0,001<\alpha(0,05)$ sehingga dapat disimpulkan terdapat perbedaan nilai rata-rata debris indeks setelah menyikat gigi dengan sikat gigi double care dengan setelah menyikat gigi dengan sikat gigi konvensional, dimana aktifitas menyikat gigi dengan sikat gigi konvensional lebih efektif dibandingkan menyikat gigi dengan sikat gigi double care. Disarankan untuk pembersihan dari deposit debris dengan hasil yang maksimal pada murid sekolah dasar direkomendasikan untuk menggunakan sikat gigi konvensional.
\end{abstract}

\section{EFFECTIVENESS OF THE USE OF DOUBLE CARE AND CONVENTIONAL TOOTHBRUSHES ON THE DEBRIS INDEX}

\section{Keywords: \\ Debris Index, Double \\ Care Toothbrush, \\ Conventional \\ Toothbrush, Student}

\begin{abstract}
The emergence of caries and periodontal disease begins with the accumulation of plaque bacteria that has accumulated on the surface of the teeth, attempts to clean it by removing plaque including using a toothbrush. The use of toothbrushes in oral physiotherapy is important to note because in the market found several kinds of toothbrushes with various types of toothbrush bristles. Using the wrong toothbrush will reduce the effectiveness of cleaning plaque on the surface of the teeth. The purpose of this study was to analyze the effectiveness of the use of double care and conventional toothbrushes on the Debris Index for SDN 05 Cilandak Timur students in 2019. This type of research was a quasi-experiment, the sample in this study was SDN 05 Cilandak Timur students totaling 32 people taken with purposive sampling technique. The results showed the Mann Whitney statistical test values obtained $\rho$ value: $0.001<\alpha(0.05)$ So it can be concluded that there is a difference in the mean value of the debris index after brushing with a double care toothbrush and after brushing with a conventional toothbrush, where brushing with a conventional toothbrush is more effective than brushing with a double care toothbrush. It is recommended that for cleaning of debris deposits with maximum results in elementary school students it is recommended to use a conventional toothbrush.
\end{abstract}

Korespondensi Penulis:

Erwin. Jl. Wijaya Kusuma No.47-48 Cilandak Jakarta Selatan, Indonesia. Email: erwin7tgm@ gmail.com

(C) Poltekkes Kemenkes Jakarta I

Jl. Wijaya Kusuma No. 47-48 Cilandak Jakarta Selatan, Indonesia

email: jurnalquality@poltekkesjakarta1.ac.id
ISSN 2655-2434

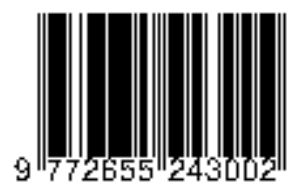




\section{Pendahuluan}

Riset Kesehatan Dasar tahun 2013, menyatakan bahwa di Indonesia terjadi peningkatan prevalensi terjadinya karies gigi pada penduduk Indonesia dibandingkan tahun 2007 lalu, yaitu dari 43,4 \% (2007) menjadi 53,2\% (2013) yaitu kurang lebih di Indonesia terdapat 93.998.727 jiwa yang menderita karies gigi (Badan Penelitian dan Pengembangan Kesehatan, 2013).

Prevalensi penduduk DKI Jakarta yang memiliki masalah kesehatan gigi dan mulut sebesar $29,1 \%$. Angka ini lebih tinggi dari rata-rata masalah kesehatan gigi dan mulut nasional yaitu sebesar 25,9 \% (Badan Penelitian dan Pengembangan Kesehatan, 2013).

Timbulnya karies dan penyakit periodontal diawali dengan adanya akumulasi bakteri plak yang menumpuk pada permukaan gigi. Plak adalah suatu deposit lunak yang terdiri dari bakteri di dalam mariks ekstraseluler dan melekat erat pada permukaan gigi atau struktur keras lainnya dalam mulut. Usaha yang dapat dilakukan dalam pembuangan plak sebagai etiologi primer dari berbagai penyakit gigi dan periodontal salah satunya menggunakan sikat gigi (Putri et al., 2008).

Kebiasaan menyikat gigi yang baik akan bermanfaat menghilangkan dan mengganggu pertumbuhan debris dan plak, membantu membersihkan sisa makanan yang menempel pada gigi, menstimulasi jaringan gingival dan menghilangkan bau mulut yang tidak diinginkan (Shaluhiyah et al., 2016).

Usia sekolah dasar merupakan saat yang ideal untuk melatih kemampuan motorik seorang anak, termasuk di antaranya menyikat gigi. Potensi menyikat secara baik dan benar merupakan faktor yang cukup penting untuk pemeliharaan kesehatan gigi dan mulut. Berhasilnya pemeliharaan kesehatan gigi dan mulut juga dipengaruhi oleh faktor pengunaan alat, metode penyikatan gigi, serta frekuensi dan waktu penyikatan yang tepat. Kelompok anak usia sekolah dasar ini termasuk kelompok rentan untuk terjadinya kasus kesehatan

(C) Poltekkes Kemenkes Jakarta I

Jl. Wijaya Kusuma No. 47-48 Cilandak Jakarta Selatan, Indonesia email: jurnalquality@poltekkesjakarta1.ac.id gigi dan mulut, sehingga perlu diwaspadai atau dikelola secara baik dan benar (Gopdianto, et al, 2014)

Kelalaian menyikat gigi secara baik bagi murid sekolah dasar akan berdampak pada kebersihan gigi dan mulut yang buruk sehingga akan memicu masalah kesehatan gigi seperti karies gigi yang rentan terjadi kelompok umur ini gigi geligi murid masih pada periode gigi bercampur. Murid sekolah dasar merupakan kelompok usia yang kritis terhadap terjadinya karies gigi dan mempunyai sifat khusus yaitu transisi pergantian gigi susu ke gigi permanen. Anak usia 8-10 tahun prevalensi karies gigi mencapai 60-85\% (Cahyati, 2013).

Penggunaan sikat gigi dalam oral fisioterapi penting untuk diperhatikan, karena dipasaran ditemukan beberapa macam sikat gigi dengan berbagai jenis bulu sikat gigi. Penggunaan sikat gigi yang salah, selain mengurangi keefektifan dalam membersihkan plak di permukaan gigi juga dapat menimbulkan kerusakan pada jaringan penyangga gigi. Sehingga ukuran sikat gigi harus disesuaikan dengan kebutuhan setiap individu (Putri et al., 2008)

Tujuan penelitian ini untuk mengetahui Efektifitas penggunaan sikat gigi double care dan sikat gigi konvensional terhadap Debris Index pada siswa SDN 05 Cilandak Timur Tahun 2019

\section{Metode}

Jenis penelitian yang digunakan adalah quasy eksperiment. Pengambilan sampel ini menggunakan teknik purposive sampling.

Jumlah sampel yang digunakan sebanyak 32 orang dimana sampel tersebut dibagi menjadi dua hari pengambilan data perlakuan yaitu hari pertama diberikan perlakuan dengan menggunakan sikat gigi double care sedangkan pada hari kedua diberikan perlakuan dengan menggunakan sikat gigi konvensional. Data debris indeks sampel akan dibandingkan setelah melakukan aktivitas menyikat gigi pada hari pertama dengan hari kedua. Peneliti mengkontrol teknik menyikat gigi sampel dengan ISSN 2655-2434

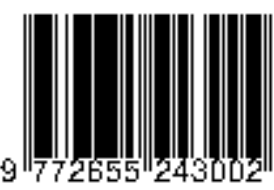


mengajarkan teknik menyikat gigi stillman sebelum intervensi. Sikat gigi double care yang digunakan jenis sikat gigi dengan tekstur bulu soft, sedangkan sikat gigi konvensional yang digunakan adalah jenis sikat gigi dengan tekstur bulu sikat medium, kedua jenis sikat gigi tersebut banyak ditemui dipasaran. Metode analisis statistik yang digunakan dalam penelitian ini adalah analisis statistik non parametric menggunakan Mann Whitney.

\section{Hasil}

Penelitian ini dilakukan di SDN 05 Cilandak Timur pada bulan Oktober 2019, hasil penelitian disajikan sebagai berikut

Tabel 1

Distribusi Frekwensi Kriteria Debris Indeks Sampel pada hari-1 (intervensi sikat Gigi double)

\begin{tabular}{cccc}
\hline \multirow{2}{*}{ No } & Kriteria Debris & \multicolumn{2}{c}{ Hari-1 } \\
\cline { 3 - 4 } & Indeks & $\mathrm{N}$ & $\%$ \\
\hline 1 & Baik & 17 & 53,1 \\
2 & Sedang & 15 & 46,9 \\
3 & Buruk & 0 & 0 \\
\hline & Total & 32 & 100
\end{tabular}

Sumber : data riset, 2019

Tabel 1 menunjukkan debris indeks sampel pada hari-1 (intervensi dengan sikat gigi double care) secara umum pada kriteria baik yang berjumlah 17 orang $(53,1 \%)$.

Tabel 2

Distribusi Frekwensi Kriteria Debris Indeks Sampel pada hari-2 (intervensi sikat Gigi konvensional)

\begin{tabular}{cccc}
\hline \multirow{2}{*}{ No } & Kriteria Debris & \multicolumn{2}{c}{ Hari-2 } \\
\cline { 3 - 4 } & Indeks & $\mathrm{N}$ & $\%$ \\
\hline 1 & Baik & 30 & 93,8 \\
2 & Sedang & 2 & 6,2 \\
3 & Buruk & 0 & 0 \\
\hline & Total & 32 & 100 \\
\hline
\end{tabular}

Sumber : data riset, 2019

Tabel 2 menunjukkan debris indeks sampel pada hari-2 (intervensi dengan sikat gigi konvensional) secara umum pada kriteria baik yang berjumlah 30 orang $(93,8 \%)$.

(C) Poltekkes Kemenkes Jakarta I

Jl. Wijaya Kusuma No. 47-48 Cilandak Jakarta Selatan, Indonesia email: jurnalquality@poltekkesjakarta1.ac.id
Tabel 3.

Uji Normalitas Data Shapiro Wilk Variabel $\rho$-value

Debris Indeks Setelah Menyikat $\quad 0,001$

Gigi dengan Sikat Gigi double

care

Debris Indeks Setelah Menyikat $\quad 0,000$

Gigi dengan Sikat Gigi

konvensional

Tabel 3 menunjukkan bahwa hasil uji normalitas data dengan Shapiro wilk menunjukkan 2 variabel tidak berdistribusi normal $\rho$-value $<\alpha(0,05)$, sehingga penelitian dilakukan uji non parametric menggunakan Mann Whitney.

Tabel 4

Hasil uji statistik mann whitney

\begin{tabular}{|c|c|c|c|c|c|}
\hline & Variabel & Mean & Selisih & $\begin{array}{c}\rho \text {-value } \\
\text { (Z- } \\
\text { hitung) }\end{array}$ & $\mathrm{N}$ \\
\hline \multirow{2}{*}{$\begin{array}{l}\text { Rata- } \\
\text { rata } \\
\text { skor } \\
\text { debris } \\
\text { indeks }\end{array}$} & $\begin{array}{l}\text { menyikat gigi } \\
\text { dengan sikat } \\
\text { gigi double } \\
\text { care }\end{array}$ & 0,74 & \multirow{2}{*}{0,34} & \multirow{2}{*}{$\begin{array}{c}0,001 \\
(3,353)\end{array}$} & \multirow{2}{*}{32} \\
\hline & $\begin{array}{l}\text { menyikat gigi } \\
\text { dengan sikat } \\
\text { gigi } \\
\text { konvensional }\end{array}$ & 0,39 & & & \\
\hline
\end{tabular}

Sumber : data riset, 2019

Tabel 4 menunjukkan setelah menyikat gigi dengan sikat gigi double care nilai rata-rata debris indeks sebesar 0,74, dan setelah menyikat gigi dengan sikat gigi konvensional nilai debris indeks menjadi 0,39 dengan selisih 0,34. Hasil uji statistik Mann Whitney diperoleh nilai $\rho$-value : $0,001<\alpha$ $(0,05)$ sehingga, dapat disimpulkan terdapat perbedaan nilai rata-rata debris indeks setelah menyikat gigi dengan sikat gigi double care dengan nilai rata-rata debris indeks setelah menyikat gigi dengan sikat gigi konvensional.

\section{Pembahasan}

Hasil penelitian pada tabel 1 dan 2 menunjukkan secara umum kriteria debris indeks ISSN 2655-2434

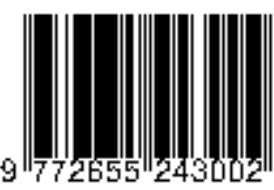


sampel baik setelah menyikat gigi pada hari-1 (dengan sikat gigi double care) maupun setelah menyikat gigi pada hari ke-2 (dengan sikat gigi konvensional) pada kriteria baik.

Hasil penelitian ini sesuai dengan penelitian Hamsar (2005) pada anak usia 9-12 tahun di SD Negeri Kecamatan Medan Petisah, menunjukkan setelah menyikat gigi baik dengan sikat gigi soft maupun medium terjadi perubahan skor plak menurun dibanding sebelum menyikat gigi.

Skor plak yang menurun menunjukkan makna bahwa dengan menyikat gigi maka permukaan gigi akan bersih dari deposit sisa makanan (debris) maupun plak gigi yang secara fisiologi akan selalu terbentuk pada permukaan gigi. Keadaan tersebut memberikan gambaran bahwa menyikat gigi yang merupakan salah satu aktivitas oral hygienis adalah metode yang sangat tepat dalam membersihkan permukaan gigi dari material lunak,

Sejalan dengan penelitian Liana \& Arbi, (2019) yang menyatakan ada hubungan tindakan menggosok gigi dengan status kebersihan gigi dan mulut murid kelas V dan VI SD di Peudada Kabupaten Bireun.

Keadaan demikian dikarenakan aktivitas menyikat gigi yang tepat akan memberikan gesekan mekanis terkontrol pada permukaan gigi yang akan mampu melepaskan perlekatan debris pada permukaan gigi, Debris mempunyai karakteristik akan terbentuk pada permukaan gigi setelah mengkonsumsi makanan dalam wujud lapisan tipis yang umumnya berwarna putih, debris tidak mempunyai daya lekat yang kuat dan mudah untuk dibersihkan dengan menyikat gigi

Menurut Cahyati (2013) debris merupakan sisa makanan yang tertinggal pada permukaan gigi, di antara gigi serta gusi pada individu tersebut. Pada waktu makan mulut menjadi kotor sesudah digunakan mengunyah makanan, gigi akan dipenuhi sisa-sisa makanan yang halus, tak lama kemudian akan menempel pada gigi membusukkan sisa-sisa makanan.

(C) Poltekkes Kemenkes Jakarta I

Jl. Wijaya Kusuma No. 47-48 Cilandak Jakarta Selatan, Indonesia email: jurnalquality@poltekkesjakarta1.ac.id
Menurut (Djamil, 2011) menyikat gigi dengan benar dapat menghilangkan plak dan kotoran dari permukaan gigi. Plak gigi tidak bisa hilang dengan berkumur-kumur saja, tetapi hanya dapat hilang dengan tindakan menyikat gigi.

Hasil penelitian pada tabel 4, menunjukkan Hasil uji statistik Mann Whitney diperoleh nilai $\rho$-value $: 0,001<\alpha(0,05)$ sehingga dapat disimpulkan terdapat perbedaan nilai rata-rata debris indeks setelah menyikat gigi dengan sikat gigi double care dengan nilai rata-rata debris indeks setelah menyikat gigi dengan sikat gigi konvensional.

Hasil penelitian ini sesuai dengan hasil penelitian yang dilakukan oleh Priyambodo \& Musdalifa (2019) tentang pengaruh kekakuan bulu sikat gigi terhadap penurunan jumlah indeks plak pada anak Sekolah Dasar Kecamatan Iwoimenda kabupaten Kolaka, diketahui hasil penelitian menggunakan uji Independent t-test menunjukkan terdapat perbedaan efektifitas dalam menurunkan jumlah plak pada penggunaan bulu sikat gigi sedang (medium) dan bulu sikat gigi lembut (soft)

Data hasil penelitian pada tabel 3 juga menunjukkan nilai rata-rata skor debris indeks setelah menyikat gigi dengan sikat gigi konvensional sebesar 0,39 lebih rendah dibandingkan nilai rata-rata skor debris indeks setelah menyikat gigi dengan sikat gigi double care sebesar 0,74. Interpretasi makna nilai debris indeks yang semakin rendah menunjukkan deposit debris yang melekat pada permukaan gigi lebih sedikit atau permukaan gigi lebih bersih. Berdasarkan hal tersebut dapat disimpulkan aktifitas menyikat gigi dengan sikat gigi konvensional lebih efektif membersihkan debris dibanding aktifitas menyikat gigi dengan sikat gigi double care.

Penggunaan sikat gigi konvensional memiliki tekstur bulu sikat sedang (medium) mempunyai kemampuan membersihkan gigi dari debris secara optimal pada frekwensi sapuan yang lebih sedikit dibanding pada penggunaan sikat gigi double care dengan tekstur bulu sikat lembut (soft) yang ISSN 2655-2434

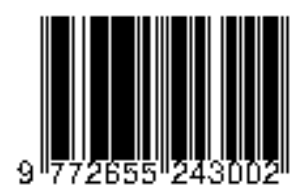


membutuhkan frekwensi sapuan lebih banyak untuk membersihkan deposit debris yang melekat. Faktor ketebalan debris akan turut berpengaruh pada aktifitas pembersihan, sehingga pada penggunaan sikat gigi double care akan membutuhkan durasi menyikat gigi yang lebih lama untuk mencapai hasil yang optimal.

Sejalan dengan pendapat Dewi (2003) bulu sikat gigi sedang (medium) lebih baik membersihkan plak daripada sikat gigi yang lembut (soft). Bulu sikat gigi lembut lebih baik dan fleksibel membersihkan daerah sulkus gingiva dan interdental, tetapi tidak dapat membersihkan plak yang tebal dan keras.

\section{Kesimpulan dan Saran}

Kesimpulan penelitian ini adalah terdapat perbedaan rata-rata debris indeks pada aktifitas menyikat gigi dengan sikat gigi double care dengan aktifitas menyikat gigi dengan sikat gigi konvensional terhadap siswa SDN 05 Cilandak Timur Tahun 2019, dengan aktifitas menyikat gigi dengan sikat gigi konvensional lebih efektif membersihkan debris dibanding aktifitas menyikat gigi dengan sikat gigi double care.

Berdasarkan kesimpulan maka saran yang diberikan adalah untuk pembersihan permukaan gigi dari deposit debris dengan hasil yang maksimal pada kelompok usia murid sekolah dasar, direkomendasikan untuk menggunakan sikat gigi konvensional dibandingkan dengan sikat gigi double care.

\section{Daftar Pustaka}

Badan Penelitian dan Pengembangan Kesehatan. (2013). Laporan Riset Kesehatan Dasar (RISKESDAS) 2013. Jakarta: Depkes RI

Cahyati, W. H. (2013). Papaya (Carica Papaya)

Consumtion To Reduce Debris Index

Konsumsi Pepaya (Carica Papaya) Dalam

Menurunkan Debris Index. Kemas, 8(2), 127-

136. Retrieved from

http://journal.unnes.ac.id/nju/index.php/kemas

Dewi, O. (2003). Pemilihan sikat gigi individual.

(C) Poltekkes Kemenkes Jakarta I

J1. Wijaya Kusuma No. 47-48 Cilandak Jakarta Selatan, Indonesia email: jurnalquality@poltekkesjakarta1.ac.id
Jakarta: Rineka Cipta.

Djamil, M. (2011). A-Z: Kesehatan Gigi: Panduan Lengkap Kesehatan Gigi. Keluarga. Solo: Tiga Serangkai Pustaka Mandiri.

Gopdianto, R., Rattu, A. J. M., \& Mariati, N. W. (2014). Status Kebersihan Mulut Dan Perilaku Menyikat Gigi Anak Sd Negeri 1 Malalayang. E-GIGI, 3(1). DOI:

https://doi.org/10.35790/eg.3.1.2015.6457

Hamsar, A. (2005). Perbandingan sikat gigi yang berbulu halus (soft) dengan sikat gigi yang berbulu sedang (medium) terhadap manfaatnya menghilangkan plak pada anak usia 9-12 tahun di SD Negeri Kecamatan Medan Petisah. Jurnal Ilmiah Pannmed.

Liana, I., \& Arbi, A. (2019). Hubungan Tindakan Menggosok Gigi Dengan Status Kebersihan Gigi Dan Mulut Pada Murid Kelas V Dan VI Sekolah Dasar Di Peudada Kabupaten Bireuen. Jurnal Bahana Kesehatan Masyarakat (Bahana of Journal Public Health), 3(1), 2629. DOI: https://doi.org/10.35910/jbkm.v3i1.189

Putri, Megananda H, et al (2008). Buku Ajar Preventive Dentistry. Bandung: Forum Komunikasi Jurusan Kesehatan Gigi Politeknik Kesehatan Depkes RI.

Priyambodo, R. A., \& Musdalifa, M. (2019). Pengaruh Kekakuan Bulu Sikat Gigi Terhadap Penurunan Jumlah Indeks Plak pada Anak Sekolah Dasar Kecamatan Iwoimenda Kabupaten Kolaka. Media Kesehatan Gigi : Politeknik Kesehatan Makassar. DOI: https://doi.org/10.32382/mkg.v18i1.890

Shaluhiyah, Z., Nugraha, P., \& Arianto (2016). Perilaku Menggosok Gigi pada Siswa Sekolah Dasar Kelas V dan VI di Kecamatan Sumberejo. Perilaku Menggosok Gigi Pada Siswa Sekolah Dasar Kelas V Dan VI Di Kecamatan Sumberejo, 9(2), 127-135. DOI: https://doi.org/10.14710/jpki.9.2.127-135 